\title{
A RELAÇÃO ENTRE A LIBERDADE DE EXPRESSÃO E A LIBERDADE RELIGIOSA NO CONSELHO DE EUROPA
}

\section{Alejandro González-Varas Ibáñez ${ }^{1}$}

RESUMEN: Este estudio analiza la evolución que ha habido en la relación entre la libertad de expresión y la libertad religiosa en el ámbito internacional. Se centra, de modo especial, en el ámbito del Consejo de Europa y la jurisprudencia del Tribunal Europeo de Derechos Humanos. Se proponen soluciones para lograr una mayor armonización del ejercicio de esos derechos, evitando así lesiones indebidas de cada uno de ellos.

PALABRAS CLAVE: Libertad de expresión. Libertad religiosa. Armonización. Consejo de Europa. Tribunal Europeo de Derechos Humanos. Naciones Unidas.

\section{LA RELACIÓN ENTRE LA LIBERTAD DE EXPRESIÓN Y LA LIBERTAD RELIGIOSA EN EL ÁMBITO DEL CONSEJO DE EUROPA}

ABSTRACT: This article addreess about the evolution that has taken place in the relationship between freedom of expression and religious freedom in the international framework. It focuses, in a main way, on the scope of the Council of Europe and the jurisprudence of the European Court of Human Rights. Solutions are proposed to achieve a greater balance between the exercise of these rights, thus avoiding undue injuries of each of them.

KEY WORDS: Freedom of expression. Religious freedom. Balance. Council of Europe. European Court of Human Rights. United Nations.

\section{Introducción}

La relación entre la libertad de expresión y la libertad religiosa se está mostrando particularmente compleja en los últimos tiempos. Una extralimitación en la expresión de mensajes aparentemente basados en la libertad religiosa ha dado lugar a que algunas personas hayan manifestado opiniones violentas e inducido a la comisión de delitos -e incluso actos terroristas- invocando una desviada interpretación de la religión.

Por otra parte, encontramos al mismo tiempo que la libertad de expresión ha desembocado en la ridiculización o mofa de las religiones y de las creencias religiosas de un amplio número de personas. Se trata de situaciones susceptibles de lesionar la libertad religiosa de la que son titulares estos individuos y las confesiones religiosas a las que pertenecen. En ocasiones incluso se ha llegado a incitar al odio o a la violencia por motivos religiosos. No en

${ }^{1}$ Profesor Titular. Facultad de Derecho. Universidad de Zaragoza (España).E-mail: agvaras@unizar.es CONPEDI LAW REVIEW | ZARAGOZA - ESPANHA | v. 4 | n. 1 | p. 81 - 99| JAN-JUN 2018 
vano, cada vez nos resultan más familiares expresiones como "discurso del odio" o hate speech, pues se han multiplicado en los últimos años el número de normas internacionales orientadas a la erradicación de estos comportamientos, y a instar a los Estados a que reformen sus ordenamientos jurídicos para combatir con mayor eficacia estos delitos. El modo en que se ejercita la libertad de expresión deja dudas sobre su legitimidad en algunas ocasiones. Episodios como las caricaturas de Mahoma, la proyección de películas donde la Virgen o Jesucristo aparecen en actitudes obscenas así como los correspondientes carteles de tono irreverente que las anuncian, o dibujos de diferente tipo que frecuentemente aparecen en revistas como la francesa Charlie Hebdo, provocan que nos preguntemos si el concepto de libertad de expresión que se invoca favorece la pacífica convivencia social o si, por el contrario, acaba desembocando en una lesión de la libertad religiosa.

En este trabajo se analiza el modo en que hasta ahora se han relacionado los conceptos de libertad de expresión y libertad religiosa en el ámbito internacional. Se centra la atención de un modo particular en el contexto del Consejo de Europa. La evolución que ha mostrado la jurisprudencia del TEDH es una muestra de cómo se han resuelto los conflictos entre ambos derechos, y cuáles son las perspectivas de futuro que, permítase adelantarlo en este momento, parecen orientarse por la prevalencia de la libertad de expresión frente a una libertad religiosa que encuentra espacios cada vez más reducidos. En las páginas que siguen se pretende explicar cuáles han sido los rasgos de tal evolución, sus motivos, y si resulta procede enderezar las líneas que se proyectan hacia el futuro.

\section{La libertad de expresión en el ámbito internacional y su relación con la libertad religiosa}

La libertad de expresión aparece reconocida en las declaraciones y pactos internacionales de derechos humanos. Ejemplo de ello lo encontramos en el artículo 19 de la Declaración Universal de Derechos Humanos, aprobada por el Consejo General de las Naciones Unidas en 1948. Allí se indica que este derecho incluye el de no ser molestado a causa de sus opiniones, el de investigar y recibir informaciones y opiniones, y el de difundirlas, sin limitación de fronteras, por cualquier medio de expresión.

Este texto ha servido de base al artículo 19 del Pacto Internacional de Derechos Civiles y Políticos, aprobado por el mismo organismo en 1966. En este lugar se hace una extensa 
referencia al derecho de libertad de expresión. Junto con las facultades a las que se refería la Declaración anteriormente mencionada, el Pacto añade que el ejercicio de este derecho entraña deberes y responsabilidades especiales. Por consiguiente, puede estar sujeto a ciertas restricciones, que deberían, sin embargo, estar expresamente fijadas por la ley y ser necesarias para el respeto de los derechos de los demás, o para la seguridad nacional y el orden público. Resulta, de este modo, interesante observar ${ }^{2}$ que este Pacto incluye una referencia expresa al ejercicio responsable de la libertad de expresión, indicación que no se encuentra especificada para el ejercicio de otras libertades.

No debe descuidarse que el artículo 20 del mismo Pacto establece que también deberá estar prohibida por la ley toda apología del odio nacional, racial o religioso que constituya incitación a la discriminación, la hostilidad o la violencia. Se trata de una limitación que es obligatoria para todos los Estados que han firmando el pacto, frente a las restricciones establecidas en el artículo 19 que muestran un carácter facultativo ${ }^{3}$. Aparte de esta característica, nos encontramos con que una de las principales problemáticas que se han suscitado a nivel internacional en torno al ejercicio de la libertad de expresión ha sido su colisión con la libertad religiosa. Más en concreto, ha resultado preocupante el denominado

\footnotetext{
* Este artículo se enmarca dentro del conjunto de actividades desarrolladas dentro del Proyecto de Investigación Libertad de expresión y prevención de la violencia y discriminación por razón de religión, financiado por el Ministerio de Economía y Competitividad de España, referencia: 76913-P y código DER 2016-76913-P, así como del Grupo de Investigación de Referencia del Gobierno de Aragón Protección de Datos, Documentación y Multiculturalismo.
}

ABREVIATURAS: ADEE: Anuario de Derecho Eclesiástico del Estado. CEDH: Convenio Europeo de Derechos del Hombre. DOUE: Diario Oficial de la Unión Europea. EHRLR: European Human Rights Law Review. HRQ: Human Rights Quarterly. IC: Ius Canonicum. JCS: Journal of Church and State. QDPE: Quaderni di Diritto e Politica Ecclesiastica. RGDCEE: Revista General de Derecho Canónico y Derecho Eclesiástico del Estado, en http://www.iustel.com. RTDH: Revue Trimestrielle des Droits de 1'Homme. SDR: Societé, Droit et Religion. STEDH: Sentencia del Tribunal Europeo de Derechos Humanos. TEDH: Tribunal Europeo de Derechos Humanos.

\footnotetext{
${ }^{2}$ Se sigue la observación que realiza Z. COMBALíA, "Libertad de expresión y difamación de las religiones: el debate en Naciones Unidas a propósito del conflicto de las caricaturas de Mahoma”, en RGDCEE, 19 (2009), p. 6. Véase también el análisis que hace en las pp. siguientes sobre los pronunciamientos del Relator de Naciones Unidas sobre las formas contemporáneas de racismo, discriminación racial, xenofobia y formas conexas de intolerancia en torno a la responsabilidad en el ejercicio de esta libertad. En relación con lo establecido en los artículos 19 y 20 del Pacto mencionado en el texto, véase también A. BUYSE, "Words of violence: 'fear speech', or how violent conflict escalation relates to the freedom of expression", en $H R Q, 36$ (2014/4), pp. 791-794. A propósito de los deberes que se derivan del ejercicio de la libertad de expresión, indica en la p. 793 y s. que aquellos justifican que pueda limitarse esa libertad. Deberán comprobarse en cada caso los intereses que entran en conflicto y valorarse, de este modo, si la limitación impuesta era realmente necesaria. Asimismo, vid. A.M. VEGA GUTIÉRREZ, "El radicalismo violento ejercicio en nombre de la religión", en EADEM (Coord.), Derechos humanos del siglo XXI. Thomson-Reuters-Aranzadi. Pamplona, 2017, pp. 321-327.

${ }^{3}$ A.M. VEGA GUTIÉRREZ, "El radicalismo violento ejercido en nombre de la religión”, cit., p. 324.
} 
“discurso del odio" o hate speech por motivos religiosos. No es este el momento de examinar en profundidad su significado ni de realizar un recorrido por los diferentes documentos que se han aprobado en relación con esta cuestión desde que comenzó ${ }^{4}$ la preocupación por la antidifamación de las religiones. Sin embargo, puede indicarse que en el ámbito internacional no resulta difícil constatar que la herida de la cristianofobia, la islamofobia o el antisemitismo, lejos de verse cauterizada, encuentra en algunas partes del planeta ecos preocupantes. En este sentido, las Naciones Unidas han alertado en repetidas ocasiones de la inquietud que les producen los actos que, difundidos en diferentes partes del mundo, suponen una apología del odio religioso o constituyen una incitación a la hostilidad o a la violencia, especialmente por motivos de filiación religiosa. También muestra su preocupación por la aplicación deliberada de estereotipos despectivos, perfiles negativos y estigmatización de personas en razón de su religión o creencias ${ }^{5}$. Por eso indica que la comunidad internacional debe adoptar las medidas necesarias para intensificar su cooperación a fin de prevenir y combatir el extremismo violento ${ }^{6}$.

Al mismo tiempo, las Naciones Unidas también han condenado la propagación de mensajes que son resultado de un ilegítimo uso de la libertad de expresión de contenidos de tipo religioso que, en ocasiones, han desembocado en la violencia y la comisión de actos terroristas realizados en nombre de la religión o creencias y que están aumentando tanto en número como en gravedad ${ }^{7}$.

\footnotetext{
${ }^{4}$ En relación con los orígenes del movimiento internacional contra la difamación de las religiones, véase R. PALOMINO LOZANO, "Libertad religiosa y libertad de expresión", en $I C$, vol. 49, no 98 (2009), p. 523 y ss. IDEM, "Libertad de expresión y libertad religiosa: elementos para el análisis de un conflicto", en RGDCEE, 29 (2012), p. 22 y ss.

${ }^{5}$ En este sentido, sin ser exhaustivos y citando solamente algunos de los pronunciamientos más recientes, véase la Resolución aprobada por la Asamblea General sobre la Lucha contra la intolerancia, los estereotipos negativos, la estigmatización, la discriminación, la incitación a la violencia y violencia contra las personas basada en la religión o creencias, A/RES/68/169, de 18 de diciembre de 2013, particularmente $\S \S 2-6$. Lo reitera en la resolución titulada del mismo modo que la precedente, de 18 de diciembre de 2014, A/RES/69/174, §§ 1-4, y 7.f) y g). Resolución de la Asamblea General de las Naciones Unidas sobre Libertad de religión o creencias, de 18 de diciembre de 2013, A/RES/68/170, §§ 4, 9, 12.c), y 14.h). y de 18 de diciembre de 2014, A/RES/69/175, §§ 4, 9 y 13. Asimismo, COMISIÓN DE DERECHOS HUMANOS DE LAS NACIONES UNIDAS, Resolución sobre la Eliminación de todas las formas de intolerancia religiosa, 2005/40, de 19 de abril de 2005, § 6. CONSEJO DE DERECHOS HUMANOS DE LAS NACIONES UNIDAS, Resolución sobre la Lucha contra la intolerancia, los estereotipos negativos, la estigmatización, la discriminación, la incitación a la violencia y la violencia contra las personas por motivos de religión o de creencias, 28/29, de 27 de marzo de 2015. IDEM, Resolución sobre Libertad de religión o creencias, A/HRC/RES/25/12, de 27 de marzo de 2014, § 3.a), b) y c). IDEM, Resolución sobre Combating intolerance, negative stereotyping and stigmatization of, and discrimination, incitement to violence and violence against, persons based on religion or belief, 16/18, de 24 de marzo de 2011.

${ }^{6}$ El Comité de Derecho Humanos ha mostrado su preocupación por que un número de Estados no ha adoptado las medidas legales que eviten este tipo de prácticas, como indica en la Observación general $n$. 11 al artículo 20 del Pacto Internacional de Derechos Civiles y Políticos, Doc.HRI/GEN/1/Rev.7/AT151, de 1983.

${ }^{7}$ Resoluciones de la Asamblea General de las Naciones Unidas sobre libertad de religión o creencias, de 18 de diciembre de 2013, §§ 5 y 6 , y de 18 de diciembre de 2014, A/RES/69/175, § 6.
} 
La preocupación, más en concreto, por el extremismo islámico y, por otra parte, la reacción contra los musulmanes, está viva también en otros contextos internacionales, como sucede en el Consejo de Europa ${ }^{8}$. Por su parte, el Parlamento Europeo también ha mostrado su preocupación por el aumento de las manifestaciones de odio y las discriminaciones de carácter anti islámico y antisemita a raíz de los atentados terroristas perpetrados en nombre del Islam ${ }^{9}$.

Como puede observarse, la libertad de expresión adquiere una importante relevancia en el ámbito internacional. Esto no ha evitado que las Naciones Unidas hayan indicado expresamente que debe hacerse un ejercicio responsable de la misma. Esta previsión adquiere particular importancia cuando puede tener frente a sí la libertad religiosa. No es infrecuente, lamentablemente, que en distintas partes del planeta se hagan pronunciamientos que incitan al odio o incluso a la violencia como consecuencia de las creencias que profesan algunas personas. Desde otro ángulo, también se constata que se formulan expresiones que apelan a ejercer actos violentos -incluidos los de tipo terrorista-basándose en pretendidos motivos religiosos. Desde luego que ni la libertad de expresión ni la libertad religiosa amparan estas conductas. También en el continente europeo se han tenido muy presentes estas situaciones y se ha intentado armonizar debidamente el ejercicio de estas dos libertades mencionadas. Se procederá a examinar a continuación cómo se ha llevado a cabo esta tarea en el Consejo de Europa.

\section{La libertad de expresión en el Consejo de Europa}

\subsection{Contenido}

\footnotetext{
8 AsAmblea PARlamentaria Del CONSEJO DE EUROPA, Resolución 1743 (2010), Islam, Islamism and Islamophobia in Europe, de 23 de junio de 2010, especialmente $\S 1,2$, y 9.

${ }^{9}$ PARLAMENTO EuROPEO, Resolución sobre la Situación de los derechos fundamentales en la Unión Europea [2002/2013(INI)], de 4 de septiembre de 2003, § 61, en DOUE, C76, de 25 de marzo de 2004. Sin embargo, algunos países europeos han endurecido sus políticas frente a la presencia del Islam en sus territorios, como indica J. CESARI, "Muslims in Europe: the snare of exceptionalism", en A. AL-AZMEH - E. FOKAS (Ed.), Islam in Europe. Cambridge University Press. Cambridge, 2007, pp. 59-61. Se detienen en explicar la reacción de los gobiernos europeos ante la presencia islámica especialmente tras los atentados terroristas del 11-S y otros acaecidos en Europa Y. YAZBECK HADDAD - T. GOLSON, "Overhauling Islam: representation, construction, and cooption of 'Moderate Islam' in Western Europe”, en JCS, vol. 49, n. 3 (2007), pp. 487 y ss. En relación con el tratamiento que ha ofrecido la Unión Europea al discurso del odio, véase Z. CoMBALÍA, "Los conflictos entre libertad de expresión y religión: tratamiento jurídico del discurso del odio”, en ADEE, 31 (2015), pp. 365-367.
} 
El Convenio Europeo de Derechos Humanos, firmado en Roma en 1950, consagra el derecho fundamental de toda persona a la libertad de expresión en el artículo 10. Allí se indica que este derecho comprende la libertad de opinión y la libertad de recibir o de comunicar informaciones o ideas sin que pueda haber injerencia de autoridades públicas y sin consideración de fronteras. En ese mismo precepto se establecen una serie de limitaciones, tal como corresponde a todo derecho fundamental, y del modo en que se comprobará en el siguiente epígrafe.

La jurisprudencia que ha emanado del TEDH con el fin de dilucidar el contenido y límites de este derecho ha sido amplia. Ha llevado a cabo esta tarea, como suele ser habitual, por medio de la ponderación de los intereses que entran en conflicto cuando esta libertad colisiona con otros derechos de las personas, o con intereses generales representados frecuentemente por el orden público.

Uno de los puntos de partida en esta actividad interpretativa ha sido afirmar que la libertad de expresión constituye uno de los fundamentos esenciales de una sociedad democrática y una de las condiciones básicas para su progreso y plenitud ${ }^{10}$. Este criterio se refiere no solo a la expresión de ideas o informaciones recibidas de forma favorable o que se consideran inofensivas, sino también en relación con aquellas que resultan opuestas, lastiman o inquietan. Es así como lo exigen el pluralismo, la tolerancia, y el espíritu de apertura sin los cuales no puede existir una sociedad democrática ${ }^{11}$. Podría decirse, por tanto, que la libertad de

\footnotetext{
${ }^{10}$ STEDH del caso Handyside contra el Reino Unido, de 7 de diciembre de 1976, $§ 49$. STEDH del caso Lingens contra Austria de 8 de julio de 1986, § 41. STEDH del caso Castells contra España, de 23 de abril de 1992, § 42. STEDH del caso Otto Preminger Institut contra Austria, de 20 de septiembre de 1994, § 49. STEDH del caso Vogt contra Alemania, de 26 de septiembre de 1995, § 52. STEDH del caso Wingrove contra el Reino Unido, de 25 de noviembre de 1996, § 52. STEDH del caso Zana contra Turquía, de 25 de noviembre de 1997, § 51. STEDH del caso Murphy contra Irlanda, de 3 de diciembre de 2003, § 65. STEDH del caso Albert-Engelman-Geselschaft MBH contra Austria, de 19 de enero de $2006 \S 25$. STEDH del caso Giniewski contra Francia, de 31 de enero de 2006, § 43. STEDH del caso Aydin Tatlav contra Turquía, de 2 de mayo de 2006, § 22. STEDH del caso Klein contra Eslovaquia, de 31 de octubre de 2006, $§ 47$. STEDH del caso Monnat contra Suiza, de 21 de diciembre de 2006, § 55 y jurisprudencia que allí cita. STEDH del caso Mamère contra Francia de 7 de febrero de 2007, § 19. STEDH del caso Pavel Ivanov contra Rusia, de 20 de febrero de 2007, § 1. STEDH del caso Chauvy contra Francia, de 29 de septiembre de 2009, § 63. STEDH del caso Ürper contra Turquía, de 20 de enero de 2010, § 35. STEDH del caso Perinçek contra Suiza, de 15 de octubre de 2015, § 196. STEDH del caso M'Bala M'Bala contra Francia, de 20 de octubre de $2015, \S 31$.

${ }^{11}$ STEDH delcaso Handyside contra el Reino Unido, de 7de diciembre de 1976, § 49. STEDH del caso Lingens contra Austria, de 8 de julio de 1986, § 41. STEDH del caso Castells contra España, de 23 de abril de 1992, § 42. STEDH del caso Otto Preminger Institut contra Austria, de 20 de septiembre de 1994, § 49. STEDH del caso Vogt contra Alemania, de 26 de septiembre de 1995, § 52. STEDH del caso Zana contra Turquía, de 25 de noviembre de 1997, § 51. STEDH del caso Murphy contra Irlanda, de 3 de diciembre de 2003, § 61. STEDH del caso AlbertEngelman-Geselschaft MBH contra Austria, de 19 de enero de 2006 § 25. STEDH del caso Giniewski contra Francia, de 31 de enero de 2006, § 43. STEDH del caso Aydin Tatlav contra Turquía, de 2 de mayo de 2006, $\$ 22$. STEDH del caso Klein contra Eslovaquia, de 31 de octubre de 2006, § 47. STEDH del caso Monnat contra Suiza, CONPEDI LAW REVIEW | ZARAGOZA - ESPANHA | v. 4 | n. 1 | p. 81 - 99| JAN-JUN 2018
} 
expresión se entiende como un bien jurídico de primordial importancia para garantizar el buen funcionamiento del sistema democrático ${ }^{12}$.

Esta situación ha dado lugar -al menos desde la perspectiva de algunos autores- a que, con el paso del tiempo, la libertad de expresión haya ido ganando espacio frente a otros derechos fundamentales, adquiriendo una posición preponderante ${ }^{13}$. Esta sobrevaloración ha desembocado en diferentes situaciones. Por una parte, el Tribunal se ha mostrado cada vez más restrictivo en la interpretación de sus límites. Sobre esta cuestión nos ocuparemos más adelante. Conviene ahora tener presente que, junto a ello, ha llegado a un punto en que ha acabado por entender que toda información o debate que tenga alguna relación con el interés público o

de 21 de diciembre de $2006 \S 55$ y 63, y la jurisprudencia allí citada. STEDH del caso Chauvy contra Francia, de 29 de septiembre de 2009, § 63. STEDH del caso Vejdeland contra Suecia, de 9 de febrero de 2012, § 53. STEDH del caso Perinçek contra Suiza, de 15 de octubre de 2015, § 196. Cfr., E. DERIEUX - L. PECH, "Existe-t-il une exception française en matière de droit à la liberté d'expression et à l'information?", en Les Cahiers de l'Institut Louis-Favoreu. Presses Universitaires d'Aix-Marseille. Aix-en-Provence, 2013, p. 157.

12 Son significativas las siguientes palabras de la STEDH del caso Zdanoka contra Letonia, de 16 de marzo de 2006 § 115: "l'article 10, qui garantit le droit à la liberté d'expression, ou l'article 11, qui consacre le droit à la liberté d'association, y compris le droit de chacun à la liberté d'association politique avec d'autres personnes au sein d'un parti. Il existe indéniablement un lien entre toutes ces dispositions, à savoir la nécessité de garantir le respect du pluralisme d'opinions dans une société démocratique par l'exercice des libertés civiques et politiques". Ofrece mayores explicaciones sobre esta cuestión E. DERIEUX - L. PECH, "Existe-t-il une exception française...", cit., p. 157.

${ }^{13}$ X. BIOY, Droits fondamentaux et libertés publiques. Montchrestien. París, 2013, p. 394. E. DERIEUX - L. PECH, "Existe-t-il une exception française...", cit., p. 157. Vid. asimismo F. FOURMENT Y P. PIOT, "La publication interdite sanctionnée comme recel de violation du secret de l'instruction", en La Semaine Juridique, 37 (2015), p. 1577. Otros autores, como es el caso de Morange han criticado el modo de obrar del TEDH porque simplemente se ha valido de unos criterios de actuación liberales empleados para resolver los casos concretos que se han sustanciado ante él. Esto no le ha permitido establecer unas líneas de actuación generales que sirvan de pauta para los jueces nacionales en el momento de ponderar la libertad de expresión y los bienes jurídicos que se pongan en conflicto. Desatendiendo las categorías jurídicas y los criterios nacionales, sin por tanto llegar a declararlos desajustados al CEDH, el Tribunal ha tendido a pronunciarse de un modo subjetivo sobre lo que es aceptable y lo que parece excesivo. Esta actitud ha desembocado en que no ha conseguido contribuir a clarificar la noción y los límites de la libertad de expresión. J. MORANGE, "Introduction générale: les aspects historiqueset généraux sur la liberté d'expression", en AA.Vv., Justice et liberté d'expression. Pulim. Limoges, 2014, p. 16. y s. Junto a ellos, otras voces indican que, en realidad, de la jurisprudencia del TEDH en esta materia se pueden inferir dos vías de actuación. La primera, que podría calificarse de liberal, parte de un concepto optimista de la democracia y del libre debate de ideas. Ofrece, como resultado, un modo de entender la libertad de expresión ciertamente amplio y sometida a las menores limitaciones posibles. Por otra parte, se percibe también una segunda corriente que, junto a la libertad, apela a los deberes y responsabilidades que le corresponde observar a quien hace uso de ella, y que no se pueden denostar. Desde esta perspectiva, se tiende a subrayar la necesidad de conciliar la libertad de expresión con los derechos y libertades que concurran en cada caso. Mientras que los primeros evidencian que la libertad de expresión debe quedar fuera de todo riesgo de censura, los segundos abogan porque su uso no lesione la dignidad humana. Ofrece este planteamiento F. KRENC, "La liberté d'expression vaut les propos qui «heurtent, choquent ou inquiètent». Mais encoré?”, en $R T D H, 106$ (2016), pp. 311-350. En relación con este debate y sus orígenes históricos, vid., F.J. ANSUÁTEGUI ROIG, "Los contextos de la libertad de expresión: paradigmas y nuevas fronteras", en Teoría \& Derecho, 21 /2017), pp. 135-140. 
general no deberá ser limitado sino por serias razones ${ }^{14}$. Antes bien, el Estado debería asegurar la circulación de ideas y permitir la intervención de cualquier persona que pueda enriquecerla ${ }^{15}$. Por otra parte, la evolución de la jurisprudencia de Estrasburgo demuestra que la libertad de expresión ha ido adquiriendo un carácter preponderante en relación con la libertad religiosa, que ha quedado algo oscurecida por la sombra de aquella, tal como se podrá comprobar más adelante.

Dentro de este contexto, el TEDH ha encontrado algunos campos donde la libertad de expresión muestra un brillo particular y otros en los que, en cambio, es preciso estrechar el rigor de sus límites. En cuanto a los primeros, es decir, los ámbitos particularmente protegidos ${ }^{16}$, encontramos la libertad artística. Dentro de ella se incluye un aspecto de particular relevancia para este estudio como es la sátira. En efecto, el Tribunal ha afirmado ${ }^{17}$ que este fenómeno constituye una forma de expresión artística y de comentario social que, a través de la deformación y la exageración de la realidad, está enfocada a provocar y agitar. Esto no quiere decir, como es obvio y del modo en que sucede con cualquier forma de expresión, que carezca de límites ${ }^{18}$. Dentro de este género podríamos especificar, a su vez, el tratamiento que han recibido las publicaciones humorísticas bajo la forma de caricatura. También aparece protegida por el Tribunal. En el caso Leroy tuvo ocasión de enjuiciar si la libertad de expresión amparaba la realización de unos dibujos de este tipo que, dependiendo de la interpretación que se les ofreciera, podrían incluso ser sospechosos de constituir una apología del terrorismo. Según

\footnotetext{
${ }^{14}$ STEDH del caso Giniewski contra Francia, de 31 de enero de 2006, § 51. STEDH del caso Animal Defenders International contra el Reino Unido, de 22 de abril de 2013, § 102. STEDH del caso Perinçek contra Suiza, de 15 de octubre de 2015, § 197: "en el ámbito del discurso político o de cuestiones de interés general, apenas hay espacio para los límites a la libertad de expresión”.

${ }^{15}$ STEDH del caso Barthold contra Alemania, de 25 de marzo de 1985, particularmente $\S 42$.

${ }^{16}$ Véase el recorrido que realiza X. BıY, Droits fondamentaux et libertés publiques, cit., p. 393 y s. Asimismo, F. KRENC, "La liberté d'expression vaut les propos...", cit., p. 311 y ss. Las diferencias entre los modos de tratar a las distintas modalidades de libertad de expresión ha impulsado a algunos autores a hablar de la "jerarquización de las libertades de expresión", como es el caso de J. MORANGE en La liberté d'expression. Bruylant. Bruselas, 2009, pp. 58-64.

${ }^{17}$ STEDH del caso Vereinigung Bildender Künstler contra Austria, de 25 de enero de 2007, § 33. SETDH del caso M'Bala M'Bala contra Francia, de 20 de octubre de 2015, § 31. En relación con la jurisprudencia del TEDH sobre la libertad de expresión artística, vid. S. GonZÁLEZ-VARAS IBÁÑEZ, "Libertad de expresión: régimen jurídicoadministrativo sustantivo y procesal", en P.J. TENORIO SÁNCHEZ, La libertad de expresión. Su posición preferente en un entorno multicultural. Wolters Kluwer. Madrid, 2014, pp. 434-437. Ofrece una definición de sátira -desde un punto de vista jurídico- y su relación con otros derechos, especialmente la libertad religiosa, M. PARISI, "Satira e religioni nel prisma della libertà di espressione. Verso una ridefinizione dei confini della manifestazione del pensiero?", en $Q D P E, 2015 / 2$, pp. 389-409. Sobre satira y Derecho, cfr. Historia de la regulación y consideración legal de las caricaturas: F. GRAS, "La tradition française de protection des caricatures", en Légicom, 54 (2015/1), pp. $5-15$.

${ }^{18}$ Véase al respecto la explicación que ofrece el TEDH en la sentencia del caso M'Bala M'Bala contra Francia, de 20 de octubre de $2015, \S 39$.
} 
Estrasburgo, estas manifestaciones no significaban que se estuviera atentando directamente contra los derechos fundamentales o los valores que sustentaban el orden político y jurídico, ni daban lugar tampoco a una apología de actos terroristas de modo que cayeran fuera del ámbito de protección de la libertad de expresión ${ }^{19}$. Continuaba afirmando ${ }^{20}$ que, en este tipo de situaciones, debía dilucidarse si había habido un equilibrio entre el derecho fundamental de la persona a la libertad de expresión, y el derecho legítimo de una sociedad democrática a protegerse contra las actividades de las organizaciones terroristas ${ }^{21}$.

Asimismo, guarda particular relevancia el ámbito político ${ }^{22}$. En virtud de ello, reconoce que las personas que se dedican a esta actividad disfrutan de una libertad de expresión más amplia. Es propio de una sociedad democrática defender el debate político libre, pues es la base de esa misma sociedad. Por eso mismo, la libertad de expresión en este ámbito no debería encontrarse limitada sino solo por razones imperiosas. Tal como ha indicado el mismo Tribunal "la libertad de expresión, preciosa para cualquier persona, lo es muy particularmente para un elegido del pueblo: representa a sus electores, expone sus preocupaciones y defiende sus intereses"23.

La libertad de prensa merece también una atención detenida. Si bien no puede trasgredir determinados límites fijados, especialmente, con vistas a la defensa del orden y de la protección de la reputación ajena, le incumbe comunicar informaciones e ideas sobre cuestiones políticas u otros temas de interés general en una sociedad democrática ${ }^{24}$. Su importancia no radica solo

\footnotetext{
${ }^{19}$ STEDH del caso Leroy contra Francia, de 6 de abril de 2009, § 27.

${ }^{20}$ Ibid., $\$ 37$.

${ }^{21}$ Sobre estas cuestiones, cfr. G. GonZALEZ, "Liberté d'expression et convictions religeuses dans la jurisprudence de la Cour européenne des Droits de l'Homme", en Cahiers de la Recherche sur les Droits Fondamentaux, 8 (2010), p. 99 y s.

${ }^{22}$ STEDH del caso Lingens contra Austria, de 8 de julio de 1986, § 42. STEDH del caso Castells contra España, de 23 de abril de 1992, § 42. STEDH del caso Wingrove contra el Reino Unido, de 25 de noviembre de 1996, § 58. STEDH del caso Zana contra Turquía, de 6 de julio de 2004, §§ 32-36. STEDH del caso Monnat contra Suiza, de 21 de diciembre de $2006 \S \S 58$ y 60. STEDH del caso Willem contra Francia, de 16 de julio de 2009 , $\$ 32$ y s. STEDH del caso Féret contra Bélgica, de 10 de diciembre de 2009, § 63. En relación con esta materia, vid. E. DERIEUX - L. PECH, "Existe-t-il une exception française...", cit., p. 157. M. HOTTELIER - E. MCGREGOR, "La liberté d'expression: regards croisés sur ses sources, son contenu et ses fonctions", en Cahiers de la Recherche sur les Droits Fondamentaux, 8 (2010), p. 15.

${ }^{23}$ STEDH del caso Castells contra España, de 23 de abril de 1992, § 42. Asimismo, STEDH del caso Willem contra Francia, de 16 de julio de 2009, § 32, y STEDH del caso Féret contra Bélgica, de 10 de diciembre de 2009, $\S 65$.

${ }^{24}$ STEDH del caso Lingens contra Austria, de 8 de julio de 1986, § 41 y s. STEDH del caso Castells contra España, de 23 de abril de 1992, § 43. STEDH del caso Chauvy contra Francia, de 29 de septiembre de 2009, § 67, y jurisprudencia allí citada. Véase también la STEDH del caso Monnat contra Suiza, de 21 de diciembre de 2006, passim, así como la sentencia del caso Flux contra Moldavia, de 29 de julio de 2008. STEDH del caso Ürper contra Turquía, de 20 de enero de 2010, $§ 36$. Sobre el alcance de la libertad de prensa y las restricciones correspondientes
} 
en el interés de ofrecer esas informaciones e ideas, sino en el derecho que tiene el público de recibirlas ${ }^{25}$. Si no pudiera obrar de este modo, no podría llevar a cabo su función de "perro guardián" de la democracia ${ }^{26}$. Por otra parte, el Tribunal extiende esta libertad hasta el punto de afirmar que alcanza la posible aplicación de un cierto grado de exageración o incluso de provocación por parte del periodista ${ }^{27}$. Debe añadirse que la libertad de prensa no abarca solo esta posibilidad de transmitir y recibir mensajes e informaciones, sino que se extiende también al modo de difusión. Por tanto, el artículo 10 del CEDH está protegiendo también el pluralismo en los medios de comunicación y la diversidad de contenidos que difundan ${ }^{28}$.

El favor hacia la libertad de prensa no ha evitado que, en algunos casos, el TEDH haya admitido que los poderes públicos puedan adoptar medidas preventivas de tal modo que se prohíba una determinada publicación. Sin embargo, advierte que en estos casos debe actuarse con la mayor precaución, teniendo en cuenta que el margen de apreciación de los Estados para imponer estas medidas es más reducido de lo que corresponde a situaciones ordinarias ${ }^{29}$. Es más, estas medidas deberán aparecer dentro de un marco legal particularmente estricto en relación con la delimitación de esta prohibición preventiva y que permita un eficaz control jurisdiccional contra los posibles abusos que puedan presentarse ${ }^{30}$. Asimismo, tales actuaciones no pueden suponer una presunción de culpabilidad del periodista, ni tampoco deben llegar a disuadir de publicar textos de ese mismo tipo en el futuro y dificultar, de esta manera, el desarrollo de la actividad profesional ${ }^{31}$. Este modo de actuar supondría una lesión desproporcionada a la libertad de expresión.

a su limitación, vid. asimismo STEDH del caso Fatullayev contra Azerbayán, de 4 de octubre de $2010, \S 82$. STEDH del caso Animal Defenders International contra el Reino Unido, de 22 de abril de 2013, § 102.

${ }^{25}$ STEDH del caso Flux contra Moldavia, de 29 de julio de 2008, § 24. STEDH del caso Ürper contra Turquía, de 20 de enero de 2010, $§ 36$. STEDH del caso Animal Defenders International contra el Reino Unido, de 22 de abril de $2013, \S 102$.

${ }^{26}$ STEDH del caso Flux contra Moldavia, de 29 de julio de 2008, § 24. STEDH del caso Fatullayev contra Azerbayán, de 4 de octubre de 2010, § 88. Sobre esta cuestión, E. DERIEUX - L. PECH, "Existe-t-il une exception française...", cit., p. 157.

${ }^{27}$ STEDH del caso Albert-Engelman-Geselschaft MBH contra Austria, de 19 de enero de $2006 \S 32$.

28 STEDH del caso Animal Defenders International contra el Reino Unido, de 22 de abril de 2013, § 101 y jurisprudencia que allí cita.

${ }^{29}$ STEDH del caso Ürper contra Turquía, de 20 de enero de 2010, §§ 39-45. STEDH del caso RTFB contra Bélgica, de 15 de septiembre de 2011, $\S 105$. Esta última sentencia admite que, en casos, excepcionales, puedan admitirse medidas preventivas, pero esto puede provocar un retraso en la publicación de la información que la prive de interés. Por lo demás, se trata de medidas en sí mismas peligrosas que requieren de un examen atento para su aplicación, y deben aplicarse dentro de un contexto legal en que están previstos mecanismos de control jurisdiccional que permitan comprobar si el establecimiento de ese control previo está justificado.

${ }^{30}$ STEDH del caso RTFB contra Bégica, de 15 de septiembre de 2011, § 105.

${ }^{31}$ STEDH del caso Ürper contra Turquía, de 20 de enero de 2010, § 43. En realidad, no se deben admitir tales limitaciones a la libertad de expresión de los periodistas -sean preventivas o no- que les disuadan a seguir CONPEDI LAW REVIEW | ZARAGOZA - ESPANHA | v. 4 | n. 1 | p. 81 - 99| JAN-JUN 2018 
Por otra parte, el favor que la jurisprudencia muestra hacia la libertad de prensa puede llegar a suponer, al mismo tiempo, unas mayores dificultades a la hora de encausar al profesional que hace un uso indebido de la libertad de expresión. Desde el punto de vista de quien ejercita este derecho, esta tendencia fácilmente supondrá una satisfacción. Pero no será así en el caso de quienes son titulares de otros derechos que pueden verse $\operatorname{afectados}^{32}$. En cualquier caso, el propio Tribunal ${ }^{33}$ recuerda que la salvaguarda de los derechos de los periodistas en el ejercicio de sus funciones que proporciona el artículo 10 del CEDH está sujeta a que actúen de buena fe y de acuerdo con su ética profesional, de modo que ofrezcan una información veraz y fiable. La posibilidad de que se constate este fenómeno ha llevado a algunos autores a proponer que los periodistas intensifiquen su formación sobre cuestiones legales, e incluso que se actualice su código deontológico ${ }^{34}$.

Finalmente, puede indicarse que se ha sumado más recientemente a este conjunto de ámbitos particularmente protegidos el de las $\mathrm{ONG}$, en cuanto privilegiados vehículos de transmisión de ideas. En este sentido, en términos que recuerdan de un modo cercano a otros ya expresados hasta ahora, el Tribunal sostiene que en el momento en que una ONG reclama la atención de la opinión sobre materias de interés público, ejerce una función de guardián público semejante por su importancia al que asume la prensa ${ }^{35}$.

Tal como se adelantaba, junto a estos ámbitos donde la libertad de expresión está particularmente protegida, aparecen otros donde se produce lo contrario. Así sucede con el caso de la pornografía, o la libertad de expresión de los funcionarios públicos ${ }^{36}$. Por otra parte, se

trabajando y ofreciendo informaciones de interés para el público, según la STEDH del caso Fatullayev contra Azerbayán, de 4 de octubre de 2010, § 102.

${ }^{32}$ F. TULKENS, "Liberté d'expression, liberté de presse: les procédures préventives et répressives sont-elles en voie d'extinction juridique?", en S. VAN DROOGHENBROECK - P. WAUTELET, Droits fondamentaux en mouvement. Anthemis. Lièje, 2012, p. 10. Según este autor, cabría preguntarse si las medidas preventivas, así como las represivas en esta materia no están en vías de extinguirse en relación con la actividad de los profesionales de la información. Por una parte, las medidas de carácter preventivo no parecen accionarse. Y, por otro lado, se aprecia de hecho una inmunidad penal creciente en relación con los delitos relacionados con el ejercicio de las actividades de prensa.

33 STEDH del caso Flux contra Moldavia, de 29 de julio de 2008, § 26. STEDH del caso Fatullayev contra Azerbayán, de 4 de octubre de 2010, § 95. También el TEDH, en la sentencia del caso Monnat contra Suiza, cit., $\S \S 65$ y 67 , ha apelado al conjunto de deberes y responsabilidades que asumen los periodistas, así como que el desarrollo de sus funciones está subordinado a actuar siempre de buena fe y que las informaciones que ofrezca sean fiables.

${ }^{34}$ F. TULKENS, "Liberté d'expression, liberté de presse...", cit., p. 27 y s.

${ }^{35}$ STEDH del caso Animal Defenders International contra el Reino Unido, de 22 de abril de 2013, § 103.

${ }^{36}$ E. DERIEUX - L. PECH, "Existe-t-il une exception française...”, cit., p. 157. En relación con las restricciones en su libertad de expresión a las que pueden verse sometidos los funcionarios públicos, véase la STEDH del caso Vogt contra Alemania, de 26 de septiembre de 1995. 
presentan otras situaciones que es que estén sometidas a unas mayores o menores limitaciones, sino que se considera que se encuentran directamente fuera del alcance de la protección del artículo 10 del CEDH. Por tanto, no recibirán ningún tipo de protección o, incluso, los Estados podrían sancionar a quienes las profirieran. Ejemplo de ello es el discurso del odio -o hate speech- o el negacionismo ${ }^{37}$. En cualquier caso, estas cuestiones deben examinarse dentro del contexto general de los límites establecidos a este derecho. A ello se procederá a continuación.

\subsection{Límites a su ejercicio}

Se admita un concepto más amplio o más restringido de la libertad de expresión, no cabe duda de que en ningún caso podrá entenderse que es un derecho fundamental que carezca de límites. El segundo parágrafo del artículo $10 \mathrm{del} \mathrm{CEDH,} \mathrm{tal} \mathrm{como} \mathrm{se} \mathrm{ha} \mathrm{adelantado,} \mathrm{se} \mathrm{encarga}$ de establecerlos ${ }^{38}$. Como sucede con todos los derechos fundamentales, su ejercicio lleva consigo la asunción de unos deberes y responsabilidades. De este modo, quien ejercita este derecho tiene a su vez la obligación correspondiente de evitar expresiones que sean gratuitamente ofensivas para un tercero y, en consecuencia, le lesione sus derechos. Por otra

\footnotetext{
${ }^{37}$ En relación con el negacionismo, véase HAUPAIS, N., "Sur de nouveaux concepts onusiens: la diffamation des religions et la lutte contre les «phobies» religieuses", en $S D R$, 2010/1, pp. 29-43. É. JAKHIAN, "Négationisme et Pénalisation", en AA.Vv., Mélanges en l'honeur du Professeur Petros J. Pararas. Sakkoulas-Bruylant. AtenasBruselas, 2009, pp. 269-281. B. JOUANNEAU, "Répression du négationnisme: la voix disonante", en Légicom, 54 (2015/1), pp. 59-67. A. LÓPEZ-SIDRO LÓPEZ, "Negacionismo y discurso de odio en España", en F. PÉREZ-MADRID - M. GAS AIXENDRI, La gobernanza de la diversidad religiosa. Thomson-Reuters-Aranzadi. Pamplona, 2013, pp. 75-99. N. MALLET-PoujOL, "Liberté d'opinion et droits de l'histoire: perspectives récentes", en Légicom, 54 (2015/1), pp. 45-58. En cuanto al discurso del odio, hay abundantes textos emanados del Consejo de Europa, así como jurisprudencia del TEDH que lo condenan. Véase sobre ello, dentro de la amplia jurisprudencia que exite, Z. COMBALÍA, "Los conflictos entre libertad de expresión y religión...", cit., pp. 359-365. A. LóPEZ-SIDRO LÓPEZ, "Yihadismo y libertad religiosa. Reflexiones desde la jurisprudencia española y del TEDH", en RGDCEE, 45 (2017), pp. 25-29. I. MARTín SÁNCHEZ, "El discurso del odio en el ámbito del Consejo de Europa", en RGDCEE, 28 (2012), pp. 1-33. J. MARTíNEZ TORRÓN, "Libertad de expresión y libertad religiosa en la jurisprudencia del Tribunal Europeo de Derechos Humanos", en QDPE, 2008/1, pp. 36-39. IDEM, "Libertad de expresión y libertad de religión. Comentarios en torno a algunas recientes sentencias del Tribunal Europeo de Derechos Humanos", en RGDCEE, 11 (2006), p. 18. R. PALOMINO LOZANO, "Libertad religiosa y libertad de expresión", cit., pp. 531-536. F. PÉREZ-MADRID, "Incitación al odio religioso o "hate speech" y libertad de expresión", en RGDCEE, 19 (2009), pp. 1-6. En cuanto al discurso del odio como límite del derecho de libertad de expresión en la jurisprudencia del TEDH, véase J. FERREIRO GALGUERA, "Libertad de expresión y sensibilidad religiosa: estudio legislativo y jurisprudencial", en RGDCEE, 35 (2014), p. 50.

${ }^{38} \mathrm{El}$ artículo 10.2 del CEDH indica expresamente que "el ejercicio de estas libertades, que entrañan deberes y responsabilidades, podrá ser sometido a ciertas formalidades, condiciones, restricciones o sanciones, previstas por la ley, que constituyan medidas necesarias, en una sociedad democrática, para la seguridad nacional, la integridad territorial o la seguridad pública, la defensa del orden y la prevención del delito, la protección de la salud o de la moral, la protección de la reputación o de los derechos ajenos, para impedir la divulgación de informaciones confidenciales o para garantizar la autoridad y la imparcialidad del poder judicial".
} 
parte, este modo de actuar no contribuye en modo alguno a alimentar un debate público capaz de favorecer el progreso en materias de interés general para las personas ${ }^{39}$.

El TEDH continúa indicando que los límites tienen que interpretarse de un modo restrictivo, sobre todo cuando afecta a alguna de las materias que antes identificamos como particularmente protegidas. Esto no quiere decir, como es obvio, que su ejercicio sea ilimitado. Tal como ha afirmado el mismo Tribunal en relación con la libertad de discusión política -como podría predicarse de cualquier otro aspecto- "no posee un carácter absoluto" 40 . Tampoco debe olvidarse que la libertad de expresión, no debería limitarse mediante medidas preventivas, sino represivas $^{41}$.

En cuanto a los límites de este derecho, existe una amplia jurisprudencia que, partiendo del análisis que realiza del artículo 10.2 del $\mathrm{CEDH}$, permite obtener las siguientes conclusiones $^{42}$. En primer lugar, debe tenerse presente que los límites tienen que estar previstos en la ley. Esto significa también que el texto normativo debe ser accesible y previsible, y también comprensible ${ }^{43}$.

En segundo lugar, esa limitación tiene que responder a fines legítimos, tal como vienen identificados en el segundo párrafo del artículo décimo del CEDH. Finalmente, tales límites tienen que ser necesarios en una sociedad democrática y responder a una necesidad social imperiosa $^{44}$. Este criterio se traduce en que haya proporcionalidad entre la medida limitadora y el objetivo que se persigue. Dicho de otro modo, se trata de que las ventajas que se obtienen con la limitación compensen a los sacrificios que esta implica para los que ejercen la libertad

\footnotetext{
${ }^{39}$ STEDH del caso Otto Preminger Institut contra Austria, de 20 de septiembre de 1994, § 49. STEDH del caso Giniewski contra Francia, de 31 de enero de 2006, § 43. STEDH del caso Monnat contra Suiza, de 21 de diciembre de $2006 \S 58$. STEDH del caso Fatullayev contra Azerbayán, de 4 de octubre de 2010, § 95.

${ }^{40}$ STEDH del caso Castells contra España, de 23 de abril de 1992, § 46.

${ }^{41}$ C. Denizeau, Droit des libertés fondamentales. Vuibert. París, 2012, p. 62.

${ }^{42}$ Pueden inferirse estas conclusiones de la práctica totalidad de las sentencias aquí citadas, pues se trata de una materia reiterada.

${ }^{43}$ Véanse, entre los múltiples pronunciamientos que se refieren a esta cuestión, los principios sentados desde las sentencias del caso Sunday Times contra el Reino Unido, de 26 de abril de 1979, §§ 49-53. Más recientemente, STEDH del caso RTFB contra Bélgica, de 15 de septiembre de 2011, §§ 103 y s. En relación con la exigencia de que los límites a la libertad de expresión -tal como afirma el CEDH-estén previstos en la ley, véase M.L. CUERDA ARNAU, "Libertad de expresión y crítica política a la luz de la jurisprudencia del Tribunal Europeo de Derechos Humanos", en Teoría \& Derecho, 2013/3, p. 217 y s.

${ }^{44}$ STEDH del caso Vogt contra Alemania, de 26 de septiembre de 1995, § 52. STEDH del caso Zana contra Turquía, de 25 de noviembre de 1997, § 51. STEDH del caso Monnat contra Suiza, de 21 de diciembre de 2006 § 55 y las sentencias expresamente mencionas en ese lugar. STEDH del caso Mamère contra Francia de 7 de febrero de 2007, § 19. STEDH del caso Chauvy contra Francia, de 29 de septiembre de 2009, § 64. STEDH del caso Fatullayev contra Azerbayán, de 4 de octubre de 2010, § 82. STEDH del caso Perinçek contra Suiza, de 15 de octubre de 2015, § 196.
} 
de expresión y para la sociedad en general ${ }^{45}$. El Tribunal considera que serán los Estados quienes tengan que valorar si esa exigencia social es realmente existente, para lo cual gozarán de un cierto margen de apreciación ${ }^{46}$. Este criterio obliga a los Estados a establecer medidas proporcionales en relación con el objetivo previsto.

El TEDH deberá comprobar si las medidas restrictivas que han adoptado los Estados se hallan justificadas. Como ha afirmado en reiteradas ocasiones ${ }^{47}$, su función no consiste en sustituir a las autoridades nacionales en la toma de estas decisiones, sino en verificar la relación que media entre esas medidas y el artículo 10 del CEDH. Esto no significa que esta supervisión quede limitada a comprobar si el Estado actuó de forma razonable, cuidadosa, y de buena fe. Antes bien, el TEDH debe revisar si se produjo la pretendida interferencia en el ejercicio de la libertad de expresión atendiendo a la situación del caso concreto. Debe determinar, en particular, si las razones que han aducido las autoridades nacionales para limitar el ejercicio de este derecho en ese caso han sido relevantes y suficientes, si la medida adoptada es proporcionada con el fin legítimo perseguido y, en definitiva, si han actuado en conformidad con los principios en los que se fundamenta el artículo 10 del Convenio.

\section{Conflictos entre libertad de expresión y libertad religiosa y la posición del TEDH}

Tal como se ha indicado al hablar de los límites generales a la libertad de expresión en el marco del Consejo de Europa, el Tribunal de esta organización ha entendido que los derechos van acompañados de las correspondientes responsabilidades. Una de estas consiste, trasladándonos al contexto de las creencias religiosas, en evitar expresiones que sean gratuitamente ofensivas para otros y que lesionen su libertad religiosa, y que además no contribuyen a un debate público que promueva el progreso en los asuntos del género humano ${ }^{48}$. Se trata de un criterio, por lo demás, compartido por la Comisión de Venecia del Consejo de

\footnotetext{
45 J. FerReIro GALGUERA, "Libertad de expresión y sensibilidad religiosa...”, cit., p. 49.

${ }^{46}$ Entre otras, STEDH del caso Ürper contra Turquía, de 20 de enero de 2010, § 35.

${ }^{47}$ Pueden apreciarse estos contenidos prácticamente en todas las sentencias hasta ahora citadas. Valga por todas la STEDH del caso Fatullayev contra Azerbayán, de 4 de octubre de 2010, §§ 83 y 84.

${ }^{48}$ STEDH del caso Otto Preminger Institut contra Austria, de 20 de septiembre de 1994, § 49. STEDH del caso Giniewski contra Francia, de 31 de enero de 2006, § 44. STEDH del caso Aydin Tatlav contra Turquía, de 2 de mayo de 2006, § 23. STEDH del caso Klein contra Eslovaquia, de 31 de octubre de 2006, § 47.
} 
Europa $^{49}$. En consecuencia, nada evita que, en una sociedad democrática, pueda considerarse necesario prevenir o incluso sancionar ataques impropios hacia la sensibilidad religiosa de los ciudadanos, o -llegado el caso- contra objetos de veneración religiosa ${ }^{50}$. En este tipo de situaciones, está legitimado que se prohíban imágenes dibujadas o proyectadas por medios audiovisuales o difundidas a través de cualquier otro medio.

Esto no evita que quienes profesan creencias religiosas no deban pensar que estarán exentos de recibir críticas. Deberán tolerar y aceptar que otros nieguen sus creencias religiosas o que incluso propaguen doctrinas hostiles a su $\mathrm{fe}^{51}$. Sin embargo, el modo de expresarse esa oposición o rechazo a las creencias religiosas puede llegar a suponer responsabilidad para el Estado, sobre todo en lo que afecta a su función de garante del disfrute pacífico de los derechos garantizados en el artículo 9 del CEDH, que recoge la protección del derecho fundamental de libertad religiosa ${ }^{52}$. Por eso el TEDH reitera que esta libertad puede resultar lesionada por determinadas expresiones ${ }^{53}$, lo que no puede resultar irrelevante para los poderes públicos.

Otra cuestión que debe tenerse en cuenta es que, en las colisiones entre estos dos derechos, el TEDH afirma la necesidad de dejar un amplio margen de apreciación a los Estados. Por ello, podrán regular con flexibilidad el modo de ejercer el derecho a la libertad de expresión cuando afecte a "cuestiones susceptibles de ofender las convicciones íntimas en el ámbito de la moral y, especialmente, de la religión" 54 . Es preciso tener en cuenta que el tipo de intimidad al

\footnotetext{
${ }^{49}$ Consejo de Europa (European Commission For Democracy through LaW, Venice Commission), Report on the relationship between freedom of expression and freedom of religion: the issue of regulation and prosecution of blasphemy, religious insult and incitement to religious hatred, adoptado por la Comisión de Venecia en su $76^{\mathrm{a}}$ sesión plenaria de 17-18 de octubre de 2008, especialmente $§ 47$.

${ }^{50}$ STEDH del caso Otto Preminger Institut contra Austria, de 20 de septiembre de 1994, § 49. STEDH del caso Wingrove contra el Reino Unido, de 25 de noviembre de 1996, $\S 46$ y 52. STEDH del caso Murphy contra Irlanda, de 3 de diciembre de 2003, $\S 65$.

${ }^{51}$ STEDH del caso Otto Preminger Institut contra Austria, de 20 de septiembre de 1994, § 47. STEDH del caso Aydin Tatlav contra Turquía, de 2 de mayo de 2006, § 27.

${ }^{52}$ El texto del artículo 9 del CEDH es el siguiente: " 1 . Toda persona tiene derecho a la libertad de pensamiento, de conciencia y de religión; este derecho implica la libertad de cambiar de religión o de convicciones, así como la libertad de manifestar su religión o sus convicciones individual o colectivamente, en público o en privado, por medio del culto, la enseñanza, las prácticas y la observancia de los ritos. 2. La libertad de manifestar su religión o sus convicciones no puede ser objeto de más restricciones que las que, previstas por la ley, constituyan medidas necesarias, en una sociedad democrática, para la seguridad pública, la protección del orden, de la salud o de la moral públicas, o la protección de los derechos o las libertades de los demás".

${ }^{53}$ STEDH del caso Otto Preminger Institut contra Austria, de 20 de septiembre de 1994, § 47. STEDH del caso Giniewski contra Francia, de 31 de enero de 2006, § 43.

${ }^{54}$ STEDH del caso Wingrove contra el Reino Unido, de 25 de noviembre de 1996, § 58. Asimismo, STEDH del caso Otto Preminger Institut contra Austria, de 20 de septiembre de 1994, § 50. STEDH del caso Giniewski contra Francia, de 31 de enero de 2006, § 44. STEDH del caso Aydin Tatlav contra Turquía, de 2 de mayo de 2006, § 24. En este sentido también la STEDH del caso Klein contra Eslovaquia, de 31 de octubre de 2006, § 47.
} 
que se refiere en estos casos es diferente del derecho a la intimidad que reconoce el artículo 8 del CEDH, referido a la vida privada y familiar. En el caso que ahora comentamos, se refiere a una intimidad relacionada con las convicciones religiosas y que, por tanto, es susceptible de determinar el modo de considerarse la persona a sí misma y su modo de actuar. Por ello, necesita una cuidadosa protección ${ }^{55}$.

Otro motivo que explica el amplio margen de apreciación que ha permitido el TEDH a los Estados se basa en la necesidad de enjuiciar cada caso según el contexto. En efecto, las sensibilidades son diferentes en cada lugar y este dato permite trazar, como línea de principio, que las autoridades de cada Estado son las más cercanas a esa situación, y las que están en mejores condiciones de evaluar si se ha lesionado la libertad religiosa del receptor del mensaje. Tal como sostiene el Tribunal en la sentencia del caso Otto Preminger Institut contra Austria seguida de otras más- ${ }^{56}$, no es posible llegar a una definición exacta de lo que constituye una lesión admisible de la libertad religiosa o, al contrario, de carácter inadmisible, como consecuencia del ejercicio de la libertad de expresión.

Esto no quiere decir que el Tribunal se inhiba de juzgar estos casos o que dé automáticamente la razón a los Estados. Se trata de una afirmación de un principio -el necesario margen de apreciación de los Estados- y, sobre esa base, verifica la proporcionalidad que ha habido entre el mensaje formulado en virtud de la libertad de expresión, y la ofensa causada y su posible lesión de la libertad religiosa. Se trata, pues, de un control mínimo ${ }^{57}$, destinado a comprobar si ha habido un error de apreciación por parte de las autoridades nacionales sobre el alcance del correspondiente mensaje sobre la libertad religiosa de terceros.

El TEDH ha aplicado de modo regular estos principios como regla general para resolver los casos de conflicto entre la libertad de expresión y la libertad religiosa, especialmente cuando esta reclama su función de límite de aquella. Sin embargo, según algunos autores ${ }^{58}$, puede observarse un giro en el modo de aplicar estas premisas a los hechos, lo que indefectiblemente ha influido el signo de los pronunciamientos judiciales. En tiempos más lejanos, como aquellos en los que Estrasburgo resolvió los casos Otto Preminger Instittut y Wingrove, esa sede

\footnotetext{
${ }^{55}$ En este sentido, G. GonZALEZ, "Liberté d'expression et convictions religeuses...”, cit., p. 93.

${ }^{56}$ STEDH del caso Otto Preminger Institut contra Austria, de 20 de septiembre de 1994, § 50. Asimismo, STEDH del caso Wingrove contra el Reino Unido, de 25 de noviembre de 1996, § 58. STEDH del caso Murphy contra Irlanda, de 3 de diciembre de 2003, § 67. STEDH del caso Giniewski contra Francia, de 30 de abril de $2006, \S 44$.

57 G. GonZaLEZ, "Liberté d'expression et convictions religeuses...", cit., p. 93. Véase también J. FERREIRO GALGUERA, "Libertad de expresión y sensibilidad religiosa...", cit., p. 53.

${ }^{58}$ En este sentido, J. MARTÍNEZ TORRÓN, "Libertad de expresión y libertad religiosa...", cit., pp. 15-42.

CONPEDI LAW REVIEW | ZARAGOZA - ESPANHA | v. 4 | n. 1 | p. 81 - 99| JAN-JUN 2018
} 
entendió que la libertad de expresión -tratándose incluso de libertad de expresión artística, pues se trató fundamentalmente de proyecciones audiovisuales- llegaba a lesionar la sensibilidad religiosa de una buena parte de la población. Por eso mismo, prohibió que los correspondientes filmes continuaran proyectándose pues, en efecto, atentaban contra la libertad religiosa.

En tiempos posteriores, como ha sucedido en la resolución de casos tales como Paturel, Giniewski, o Aydin Tatlav, el TEDH sigue invocando los mismos principios de antes, solo que lo hace sobre una distinta apreciación de los hechos que ofrecen como resultado una preponderancia de la libertad de expresión sobre la libertad religiosa ${ }^{59}$. Como resultado de esta tendencia ${ }^{60}$, el TEDH sigue afirmando la necesidad de aplicar la teoría del respeto al margen de apreciación de los Estados, si bien ha tendido recientemente a su progresiva reducción a favor

\footnotetext{
${ }^{59}$ J. MARTínez TORRÓN, "Libertad de expresión y libertad religiosa...", cit., pp. 25 y 30. IDEM, "Libertad de expresión y libertad de religión...", cit, pp. 8 y 16 y s.

${ }^{60}$ Z. COMBALÍA, "Los conflictos entre libertad de expresión y religión...", cit., p. 362 y s. Observa también esta tendencia del TEDH a dar primacía al derecho de libertad de expresión sobre la libertad religiosa C. DENIZEAU, Droit des libertés fondamentales, cit., p. 254. P.J. TENORIO SÁNCHEZ, "La libertad de comunicación en Estados Unidos y Europa”, en IDEM, La libertad de expresión. Su posición preferente en un entorno multicultural, cit., pp. 124-126. En cambio, entiende que la balanza del TEDH se inclina hacia un mayor favor de la libertad de creencia que de la libertad de expresión H. LECLERC, "Laïcité, respect des droyances et liberté d'expression", en Légicom, 55 (2015/2), p. 49. Otros autores proponen otras soluciones que despiertan una cierta perplejidad. Es el caso de N. NATHWANI, "Religious cartoons and human rights. A critical legal analysis of the case Law of the European Court of Human Rights on the protection of religious feelings and its implications in the Danish affair concerning cartoons of the Prophet Muhammad", en EHRLR, 2008/4, pp. 488-507. Según este autor, las creencias religiosas de quienes son fieles de las confesiones mayoritarias en cada país no deberían ser objeto de protección, por lo que la libertad de expresión sería habitualmente preponderante. Su protección atentaría contra la neutralidad del Estado. En cambio, las creencias de los miembros de las confesiones minoritarias sí deberían estar protegidas, pero no por el respeto a la libertad religiosa, sino para evitar episodios de xenofobia o racismo. Según el autor, las personas que abrigan estas creencias forman parte de minorías étnicas -aunque es evidente que no siempre es asíy deben estar protegidos para lo cual deberán sancionarse los ataques contra sus creencias. Es evidente que los términos expuestos tienen unas carencias argumentativas importantes. Por su parte, otros autores como F.J. ANSUÁTEGUI ROIG en "Los contextos de la libertad de expresión...", cit., pp. 146-149, entienden que las creencias religiosas forman parte de la ética privada de las personas, mientras que la libertad de expresión tiene como terreno propio el de la ética pública. Según sostiene, "las dimensiones de la ética privada (en las que se incluyen las creencias religiosas) no forman parte de los contenidos de ética pública". Por ello, "el hecho de que determinadas creencias religiosas -y, por tanto, particulares, y no necesariamente generalizables- tengan un valor supremo para aquellos que las comparten no es razón suficiente para que sean elevadas a la dignidad del ordenamiento" (p. 146). En consecuencia, no le corresponde al Derecho limitar la libertad de expresión cuando se orienta a criticar la religión o las creencias personales. En realidad este tipo de conductas deberían estar limitadas por la prudencia o la educación. Desde luego que no parece del todo acertado considerar que las creencias religiosas deben quedar limitadas al ámbito de la ética privada. Es evidente que contribuirán a la formación de la ética y moral de la persona, pero por eso mismo trascenderán al ámbito público, desde el momento en que la persona actúa en sociedad, juzgará la realidad en torno en conformidad con sus parámetros éticos y querrá actuar en consecuencia con ellos, exteriorizando sus creencias. Además, ¿por qué lo religioso ha de estar excluido de lo público? ¿qué razones hay para que otros puntos de vista o ideologías sí puedan formar la ética pública y, en cambio, la religión esté excluida de ello? Asimismo, parece un tanto ingenuo dejar al arbitrio de la educación y la prudencia la salvaguardia e integridad de las creencias religiosas de las que es titular toda persona. No se trata tanto de respetar lo sagrado, sino de respetar el derecho fundamental de libertad religiosa de las personas. Por tanto, el Derecho también debería actuar para asegurar su debida garantía.
} 
de reforzar la libertad de expresión frente a la religiosa cuando -en relación con esta última- se trata de proteger los sentimientos religiosos ${ }^{61}$. En cambio, el mismo Tribunal ha estrechado los límites de la libertad de expresión cuando esta ha tenido por objeto la incitación al odio por motivos -entre otros- religiosos. Debemos recordar que, tal como ha sostenido el mismo $\mathrm{TEDH}^{62}$ - el discurso del odio basado en motivos religiosos, étnicos o culturales, representa en todo caso un peligro para la paz social y la estabilidad política de los Estados, con independencia de que tal discurso llegue o no llegue a incitar a la violencia u otros delitos.

No cabe duda de que la pretensión de erradicar el discurso del odio y la incitación a la violencia o la discriminación por motivos religiosos es plausible y necesaria en todo momento, particularmente en tiempos como los actuales. Sin embargo, no se aprecia motivo alguno para que se produzca la progresiva desprotección de la libertad religiosa en cuanto derecho que permite creer, profesar y exteriorizar libremente unas determinadas creencias sin coacciones, ni temores, ni vilipendios directos o indirectos. La secularización de la sociedad tal vez haya llegado a una banalización de lo religioso que haya provocado la relegación de la libertad religiosa a la categoría de bien jurídico de segunda categoría, incapaz de resistir al embate de cualquier otro derecho fundamental que se le oponga -en este caso, la libertad de expresión-. Quizá pueda producirse también este refuerzo de la libertad de expresión frente a todo aquello que tiene alguna relación con lo sagrado -incluida la libertad religiosa- como un recurso de los países occidentales para reafirmarse en su alta consideración de la libertad de expresión, sobre todo frente a un mundo islámico en el que lo sagrado o lo religioso en sí mismos considerados son un bien jurídico ${ }^{63}$. Tal vez nos encontremos ante un modo de subrayar lo que se considera que es un concepto propio occidental frente a unas interpretaciones de este derecho no solo

\footnotetext{
${ }^{61}$ Debe tenerse en cuenta que la interpretación actual de la relación entre libertad de expresión y libertad religiosa en el contexto del Consejo de Europa se basa en la intención de esta organización de proteger no tanto a las creencias religiosas en sí mismas, sino a las personas que las profesan. Así se indica en CONSEJO DE EUROPA (EUROPEAN COMMISSION FOR DEMOCRACY THROUGH LAW, VENICE COMMISSION), Report on the relationship between freedom of expression and freedom of religión..., cit., § 49. Véase sobre ello Z. CoMBALÍA, "Los conflictos entre libertad de expresión y religión...", cit., p. 359 y ss.

${ }^{62}$ STEDH del caso Vejdeland contra Suecia, de 9 de febrero de 2012, §§ 54 y 55. Asimismo, la STEDH del caso Féret contra Bélgica, de 10 de diciembre de 2009, § 64, advierte que en ocasiones puede ser necesario, en una sociedad democrática, prevenir o sancionar cualquier forma de expresión que propague, anime, promueva, o justifique el odio fundado en la intolerancia, ahí comprendida la religiosa.

${ }^{63}$ Sobre esta cuestión, vid. las siguientes obras de Z. COMBALÍA, El derecho de libertad religiosa en el mundo islámico. EUNSA. Pamplona, 2001. EADEM, "Libertad de expresión y difamación de las religiones: el debate en Naciones Unidas a propósito del conflicto de las caricaturas de Mahoma", en RGDCEE, 19 (2009), pp. 1-31. EADEM, "Nuevos desafíos sociales y jurídicos derivados de la presencia del Islam en las sociedades occidentales del s. XII", en Z. COMBALÍA, - M.P. DiAGO - A. GonZÁLEZ-VARAS (Coords.), Derecho e Islam en una sociedad globalizada. Tirant lo Blanch. Valencia, 2016, pp. 17-44.

CONPEDI LAW REVIEW | ZARAGOZA - ESPANHA | v. 4 | n. 1 | p. 81 - 99| JAN-JUN 2018
} 
lejanas de esta tradición, sino que dan lugar a actos violentos. En cualquier caso, y con independencia del grado de secularización de la sociedad y de la identidad de la persona que invoque el derecho de libertad religiosa, la expresión de ofensas, mofas, ridiculizaciones u obscenidades no contribuye a la paz social, ni al libre ejercicio de sus derechos por parte de terceros ni -probablemente- al enriquecimiento del debate social. Será así, especialmente, cuando tales expresiones se dirigen hacia un aspecto tan sensible para cualquier ser humano como sus creencias religiosas y convicciones más profundas. Nos encontramos, por tanto, ante un buen momento para que el TEDH se replantee continuar con su última tendencia de interpretación de la relación entre estos derechos o, más bien, valore la posibilidad de retornar a los criterios de Otto Preminger o Wingrove. Sería, por otra parte, un buen ejemplo para una buena parte de los Estados europeos. 